\title{
ANÁlise dAS OBJEÇões AO SigNifiCAdo DOS Nomes PRÓPRIOS NA TEORIA METALINGUÍstica
}

\author{
Josailton Fernandes MendonÇA
}

\begin{abstract}
In this paper I examine the three known objections to metalinguistic semantic theory of proper names: the objection of generalization, the objection of circularity, and the objection arising from Kripke's modal argument. I'm trying to demonstrate that these objections are not conclusive as refutation or rejection of metalinguistic theory. I argue that this is a not a theory of reference but rather of the meaning or semantic value of proper names. Thus, the semantic value of a proper name " $\mathrm{N}$ " is "The bearer of ' $\mathrm{N}$ '." In this approach the significance of this proper name unifies all the possibilities for its referential use and allow us to defend that the name itself is an expression of language, despite arguments to the contrary.
\end{abstract}

Keywords: Generalization; circularity; modal argument; metalinguistic; proper name.

\section{Introdução}

Um nome próprio, como entendo, denota a classe de todos aqueles indivíduos para os quais o nome tem sido dado; em outras palavras, um nome próprio aponta para uma propriedade geral — também designada como propriedade sortal — que qualifica o nome próprio como expressão de um sistema linguístico. Essa propriedade tipo, qualifica o nome próprio a ser aplicado significativamente a qualquer número de objetos, sendo literalmente expresso pela descrição "O portador de ' $N$ ". Esta propriedade está inserida no quadro das análises, desenvolvidas nos últimos anos por Brian Loar (2006), Stephen Schiffer (1978), Kent Bach (1981), Castañeda (1988), Katz (1994), François Recanati (1997) e outros. Mas há insistentes objeções a essa tese. Focalizo aqui a objeção da circularidade, a objeção da generalidade e a objeção que decorre do argumento modal.

Essas objeções são as mais contundentes na crítica a assim chamada teoria metalinguística do significado - ou valor semântico dos nomes próprios —, favorecendo o descrédito da teoria. A primeira objeção é de que a teoria viola a condição exigida de toda a teoria da referência, a saber, a não circularidade. A segunda é a de que, assumindo que a teoria metalinguística é um caso específico do descritivismo acerca da semântica dos nomes próprios, o argumento modal — que parece refutar este último - também reprova aquela. Finalmente, desde que o significado de um nome "N" é dado pela descrição "O portador de 'N", então, por paridade de raciocínio, o significado de uma palavra como "Cavalo" inclui "ser chamado 'Cavalo", isto é, ao defendermos que a análise correta do comportamento semântico dos nomes próprios é

Principia 19(3): 405-422 (2015).

Published by NEL — Epistemology and Logic Research Group, Federal University of Santa Catarina (UFSC), Brazil. 
aquela apresentada pela teoria metalinguística, devemos querer explicar a razão pela qual os nomes próprios são - de modo relevante — diferentes de outras palavras. É o argumento da generalização. Primeiramente, discuto esse argumento com base em seu exame, sustentando que os nomes próprios são expressões da linguagem; depois, analiso a objeção da circularidade; e, finalmente, observo a objeção decorrente do assim chamado argumento modal. Proponho, antes disso, apresentar as linhas gerais de minha concepção semântica dos nomes próprios, com base na qual discutirei as mencionadas objeções.

\section{A questão do significado metalinguístico dos nomes próprios}

Uma defesa possível da tese metalinguística deverá mostrar que as objeções não são conclusivas quanto a sua refutação. Nesta perspectiva, assumo como corolário a seguinte proposição: a teoria metalinguística não é uma teoria da referência. O que isso quer dizer? O problema da referência pode ser expresso como segue: como uma expressão linguística nos conecta a algo no mundo? Em particular, como explicar que o nome próprio nos conecta a algo no mundo? Uma teoria da referência propõe uma resposta a essa questão. Já a teoria do significado, como a compreendo, procura explicar como um nome próprio ou outra expressão da linguagem exerce a sua performance semântica, isto é, que regra permite que uma expressão da linguagem seja contada como nome próprio? Neste sentido, uma teoria do significado é uma teoria do valor semântico dessa expressão. Uma tradição que se formou em torno da teoria da linguagem de Mill, em particular, sua teoria dos nomes próprios, defende que o que é transmitido pelo uso de um nome próprio, é o próprio indivíduo. Portanto, o conteúdo ou valor semântico de um nome próprio é o seu referente. Na teoria metalinguística, este valor semântico não está relacionado ao referente singular.

A origem da tese metalinguística remete a um aspecto do descritivismo de Russell (1905). De acordo com ele, "nomes abreviam descrições" e descrições não nomeiam ou designam coisas, os enunciados que as envolvem têm estrutura lógica que é diferente de sua estrutura gramatical. Por exemplo, o enunciado "O $\phi$ é G" é capturada pela forma lógica da proposição $\exists x(\phi x \& \forall y(\phi y \rightarrow y=x) \& G x)$. Nesta situação, enunciados envolvendo descrições da coisa, na posição de sujeito, são decomponíveis em funções proposicionais, que expressam propriedades das coisas e não têm a função de nomear o que Frege afirma ter.

Se esta ideia é correta, o problema da referência dos nomes próprios se transforma no problema da referência das descrições definidas que, por sua vez, destituída dessa função referencial, apenas enuncia as propriedades exemplificadas ou não pelos objetos.

A teoria metalinguística é uma resposta possível ao referencialismo, ao mesmo

Principia 19(3): 405-422 (2015). 
tempo, não deixa de ser uma nova leitura de certos aspectos da teoria descritivista para os nomes próprios. Talvez, por isso mesmo, e face às progressivas retificações da teoria milliana da referência, a explicação para o comportamento semântico dos nomes próprios, sob a ótica da teoria metalinguística, apesar de correta - ao menos é o que aqui defendo - fora sujeita a contínuas rejeições, constituindo-se numa tese minoritária na discussão.

Em linhas gerais, a teoria propõe uma relação entre o nome próprio e uma descrição que faz menção ao nome. Neste sentido estrito, penso que podemos compreender que o nome próprio abrevia aquela descrição definida. Trata-se, portanto de uma relação em que, uma expressão linguística é objeto de análise em outra expressão linguística que a menciona. Temos assim, o significado sintático ou literal que caracterizará a teoria metalinguística.

Vigora, em apoio à teoria, a distinção entre característica da linguagem e característica do uso da linguagem; o significado linguístico de um enunciado e o que é comunicado pelo proferimento sincero e literal desse mesmo enunciado. Assim, o valor semântico do nome é a regra linguística representada pela descrição definida, a qual menciona o nome e que constitui o seu conteúdo léxico fundamental. Em resumo, um falante $S$ refere-se a um particular $x$, ao proferir "N", antes de tudo porque o nome próprio " $N$ " tem um valor semântico, nos termos da regra linguística que explica o seu poder referencial.

Nesta condição, penso que o fenômeno da referência singular deve considerar por um lado, a abertura semântica dos nomes próprios - definido em termos de sua liberdade de aplicar-se sempre a novos indivíduos, sem com isso constituir uma mudança semântica; por exemplo, quantas Luizas, quantas Marias, etc. existem - e, ao mesmo tempo, a propriedade geral "O portador de ' $N$ "' que como a regra semântica fundamental, reúne e justifica a universalidade dessa abertura semântica e o nome próprio como expressão, com função referencial singular.

Esclarecido esses pontos, podemos agora analisar as objeções à tese metalinguística.

\section{Objeção da generalização}

Kripke (1980) apresenta em Naming and Necessity, um desafio poderoso à teoria metalinguística acerca da semântica dos nomes próprios: se a análise dessas expressões — promovida pelas abordagens metalinguísticas — não se presta para a análise do significado das palavras em geral, por que adotá-la aos nomes próprios? O que tem de especial nestas expressões para permitir este tipo de análise? O ponto em discussão é o seguinte, de acordo com Kripke (1980, p.69):

Por exemplo, embora possa ser informativo para alguém dizer que cavalos são usados em corridas, é trivial dizer-lhe que cavalos se chamam 'Cavalos'.

Principia 19(3): 405-422 (2015). 
Portanto, isso somente poderia ser o caso porque o termo 'Cavalo' significa em nosso idioma as coisas chamadas 'Cavalo'.

Claramente, a abordagem não é muito boa como explicação do significado das palavras em geral. E, como tal, parece igualmente de pouca utilidade para analisar o significado dos nomes próprios. A objeção então, se deixa reconstruir da seguinte forma: se um nome próprio " $\mathrm{N}$ " significa "O portador de ' $\mathrm{N}$ ", então, uma palavra como "Mesa" deve significar (por analogia), "a coisa chamada "Mesa". Portanto, o desafio colocado é justificar porque os nomes próprios devem ter este tipo especial de análise.

Alguns teóricos da abordagem metalinguística, sobretudo Bach (2002), respondem ao desafio argumentando que os nomes próprios não fazem parte da linguagem, embora tenha um impacto semântico nos enunciados em que comparecem. O problema agora é demonstrar essa tese.

Kent Bach (2002) argumenta que dicionários não são incompletos por não incluírem nomes próprios, da mesma forma que o vocabulário pessoal de cada um não é mais pobre por não conhecer todos os nomes próprios. Explica Bach (2002) que no proferimento de uma frase como, por exemplo, (i) "Schopenhauer teve muita influência sobre Nietzsche", não se está proferindo uma combinação de português com alemão. Antes, na frase em português, comparecem nomes próprios que, a rigor não pertencem a uma língua particular. Nomes como "Peter" e "John", embora sejam expressões da fonética inglesa, não são itens léxicos da língua inglesa. Suas contrapartes em português, a saber, "Pedro" e "João", não são traduções desses termos na língua inglesa. E, como tal, "Peter" não é sinônimo de "Pedro", assim como "João" não é sinônimo de "John". Consequentemente, nomes como "Schopenhauer" e "Nietzsche", embora sejam expressões da fonética alemã, não pertencem ao léxico dessa língua. Daí ser possível proferir a frase (i) em língua portuguesa, sem traduzir os nomes próprios que ali comparecem.

Contudo, segundo Abbott (2004), é preciso admitir que esta tese, aparentemente, não tem apoio firme. Por exemplo, a despeito do que diz Bach (2002), nomes próprios constituem uma importante categoria gramatical. Suas fonologias pertencem às línguas particulares - "Juan" é um bem conhecido nome espanhol, "Hannah" é uma bem conhecida expressão de um nome próprio em alemão — e é preciso admitir ainda que, embora nomes não constituam itens lexicais do dicionário de qualquer língua, isso não justifica a tese de que nomes próprios são itens extralinguísticos, já que, muitas outras expressões da língua, em particular, aquelas que caíram em desuso ou aquelas que estão na vanguarda, não se apresentam em muitos dicionários. Além do mais, como lembra Geach (1962, p.26), inegavelmente, "[...] é parte do trabalho lexicográfico nos dizer que "Warsaw" é a palavra inglesa para "Warszawa"". Por fim, segundo Abbott (2004), é certo que não saber que "Shakespeare" e "London" 
são nomes próprios é seguramente uma deficiência no vocabulário pessoal. Assim, ao que parece, nomes próprios são, no mínimo, itens fonológicos e morfológicos da linguagem. Consequentemente, aquela vertente de argumentação de Bach (2002) não justifica a hipótese de que nomes próprios não pertencem a qualquer língua particular, uma vez que, ao menos do ponto de vista fonológico e morfológico, nomes próprios são expressões da linguagem. Ocorre então a necessidade de buscar a resposta ao argumento da generalidade, admitindo nomes próprios como constituintes da língua, dotados de comportamento semântico distinto das demais expressões da linguagem e capturado pela teoria metalinguística.

Katz (1994), por exemplo, argumenta que o que distingue nomes próprios de nomes comuns é o fato de que os primeiros têm um sentido metalinguístico. Este sentido toma a relação nome-portador como envolvendo uma propriedade puramente nominal.

Para Katz (1994), os sentidos são propriedades que as expressões têm em virtude das quais prescrevem certos fenômenos linguísticos, como: significado, sinonímia, ambiguidade, redundância, antinomia, etc. Nestes termos, o sentido pertence ao domínio dos objetos gramaticais, estudados na investigação da estrutura dos enunciados da língua. E, como tal, é independente de qualquer ligação intrínseca com a referência.

Se for assim, segue-se que, primeiramente, o conhecimento do sentido é condição necessária no uso literal e não literal das expressões. Por exemplo, a aplicação literal da palavra "Gorila" para Gorila e a aplicação de "Hitler" para Hitler depende do conhecimento do significado literal dessas expressões. O mesmo ocorre quando da aplicação não literal, por exemplo, a aplicação da expressão "Gorila" para designar a mascote de uma equipe esportiva, e aplicação do nome "Hitler" associado ao comportamento do professor de Lógica em sala de aula, dependem do conhecimento do significado literal dessas expressões. Em segundo lugar, desde que o sentido seja compreendido como esse fenômeno intralinguístico, não existe a necessidade de definir um nome próprio como "Aristóteles" - em termos de descrições ricas o bastante para determinar-lhe o referente - , pois uma condição prévia existe para tanto, que é o conhecimento do sentido do nome "Aristóteles", a saber, "A pessoa ou coisa portadora do nome 'Aristóteles"'.

Concernente a este último aspecto, tudo ocorre de modo diferente do que acontece com os nomes comuns. Por exemplo, o sentido literal da palavra "Gorila" ou da palavra "Vermelho", é a base para representar o modo como o referente se apresenta ao falante. No caso dos nomes próprios, isso não é suficiente, pois se exige fatores extralinguísticos na determinação desse referente, ou seja, o simples sentido não tem o poder semântico que tem no caso dos nomes comuns. Em suma, o que Katz (1994) parece sugerir é que nomes próprios são mecanismos linguísticos-formais, cujo significado não determina a referência.

Principia 19(3): 405-422 (2015). 
Bach (1994) faz restrições quanto a esta hipótese de Katz. De acordo com ele, embora um nome próprio " $\mathrm{N}$ " se defina em termos da propriedade puramente nominal "O portador de ' $\mathrm{N}$ ”, esta propriedade não manifesta o sentido do nome. Na verdade, diz Bach (1994, p.4), que tal conceito é perfeitamente dispensável na teoria metalinguística:

Para uma formulação precisa, eu concordo com Katz sobre a importância de invocar tão somente uma relação de portar que seja nominal, mas discordo dele sobre como isso deve ser feito [...] Prefiro o que eu chamo de "Teoria descritiva nominal" com seu esquema mais simples 'O portador de ' $\mathrm{N}$ ". Também invoco uma relação de portar puramente nominal, mas não a noção de sentido. Argumento que a PMT (Teoria metalinguística Pura) é desnecessariamente complexa e que a noção de sentido não faz o trabalho que Katz enfatiza.

Com efeito, Katz (1994) sugere que o sentido literal do token deriva do sentido de seu tipo. Mas, de acordo com Bach (1994), ele não explica como isso é feito. Além do mais, se o sentido é um conceito intralinguístico, ele deveria pertencer tão somente às expressões tipo e não aos tokens. Aliás, ressalta Bach (1994), que nomes próprios não parecem ter aquelas características intralinguísticas que definem o sentido segundo Katz. Por exemplo, o que podemos contar como sinônimo para "Natal" ou como antônimo de "Potengi"?

Assim, parece mais razoável, de acordo com Bach, admitir que nomes próprios não pertencem à linguagem. Contudo, a objeção da generalidade não parece dirimida, pois é preciso admitir que, no mínimo, os nomes próprios são itens fonológicos e morfológicos de qualquer língua. Logo, é preciso assumir que nomes próprios são itens lexicais da linguagem, ao menos numa acepção muito restrita.

Que nomes próprios sejam itens linguísticos num sentido mínimo, é uma tese compartilhada por Recanati (1997, p.138). De acordo com ele,
A única indicação linguisticamente transmitida [pelo nome] é a que corres- ponde à característica REF - nomeadamente, a indicação de que há uma entidade tal que um proferimento é verdadeiro se, somente se, esta entidade satisfaz o predicado. Sobre esta interpretação, a informação que o nome pró- prio transmite em virtude da convenção que associa o nome com a referên- cia, não é linguística, portanto não é parte do significado do nome próprio porque a convenção em si mesma não é linguística.

Em suma, o significado não tem o poder semântico de atribuir ou individualizar um portador para o nome, isto é, parte do contexto antes que parte da linguagem.

Isso justifica, de acordo com Recanati (1997), nomes próprios serem analisados sob o enfoque metalinguístico, enquanto que as palavras comuns não. Consideremos, por exemplo, as expressões "Sócrates" e "Vermelho". Convencionalmente, estas expressões estão associadas, respectivamente, a certo indivíduo e a certa cor. Assim, 
a convenção indica algo para cada uma das expressões: a palavra "Sócrates" é indicada para esse homem (apontando para Sócrates); a palavra "Vermelho" é associada a esta cor (apontando para um token de vermelho). Recanati (1997, p.163) chama de relatum tais associações ou indicações convencionais. A diferença então entre nomes próprios e palavras comuns é que o significado (valor semântico) desta última é estabelecido em termos do relatum, ou seja, o significado da palavra "vermelho" é o que a convenção semântica associa à palavra, neste caso, cor. Logo, "vermelho" significa a cor, não "a coisa chamada 'vermelho"'. No caso dos nomes próprios, essa associação não parte de uma convenção linguística, mas de relação - convencional de natureza não linguística - entre o nome e o seu portador. Daí, aquela associação não fixa o significado (que é de natureza linguística) do nome próprio. Contudo, desde que nomes próprios sejam expressões da linguagem, o seu significado somente pode ser fixado por uma convenção linguística — aquela que um nome próprio refere ao seu portador, ou melhor, aquela que relaciona um nome próprio "N" à descrição que o menciona "O portador de "N"'.

Portanto, admitindo que nomes próprios tenham significado, este apenas qualifica o nome como expressão referencial, isto é, revela o nome como uma expressão da linguagem a qual remete a um portador. Todavia, a referência transmitida pelo nome não é parte constituinte deste significado. Assim, como sugere Recanati (1997), a convenção que associa "Sócrates", a Sócrates não é linguística.

A meu ver, o argumento da generalização não chega a ser um problema para as teorias metalinguísticas. Kripke deixa escapar - ao formular o argumento - um dado importante, cuja ausência caracterizará o problema da generalização: a equivocidade no uso dos nomes próprios. Tal característica revela que a singularidade do ato de referir não decorre da linguagem, antes é assegurada por um conjunto de fatores extralinguísticos. Nestas condições, a única regra semântica dos nomes próprios que os qualifica como expressão da linguagem - a saber, $\mathrm{N}$ significa "O portador de 'N" - reúne todas as possibilidades de performances do nome, segundo o contexto e a intenção do falante.

\section{A objeção da circularidade}

Em Naming and Necessity Kripke (1980, p.69) estabelece a seguinte condição (C) para qualquer teoria descritivista dos nomes próprios:

(C) Para que uma teoria tenha êxito, a explicação não pode ser circular. As propriedades usadas na votação não devem supor elas mesmas a noção de referência, de tal maneira que estas resultem ao fim impossível de eliminar.

Um exemplo claro deste tipo de violação é apresentada por Devitt (2006, p.521): suponha uma teoria que aponta como descrição identificadora, "O indivíduo cha- 
mado N". Neste caso, admitiríamos a seguinte transmissão da referência: um falante $y$, ao proferir $\mathrm{N}$, estará associando $\mathrm{N}$ à descrição "O indivíduo a que $x$ refere por $\mathrm{N}$ ", um falante $z$, ao proferir $\mathrm{N}$ estará associando $\mathrm{N}$ à descrição "O indivíduo a que $y$ refere por $\mathrm{N}$ ", mas $y$ refere por $\mathrm{N}$ ao indivíduo que $x$ refere por $\mathrm{N}$, e $x$ refere por $\mathrm{N}$ ao "O indivíduo chamado N". Mas quem é "O indivíduo chamado N"? Aquele que o falante $y$ associa à descrição "O indivíduo que $x$ refere por $\mathrm{N}$ ". Uma teoria assim infringiria a condição (C).

Kripke (1980) atribui tal situação à teoria metalinguística. E, dessa forma, justifica a rejeição de hipóteses como a sugerida por Kneale (1962) para o conteúdo semântico dos nomes próprios. Segundo Kneale (1962), "é obviamente trivial que Sócrates é chamado Sócrates" porque Sócrates significa "O individuo chamado 'Sócrates"'. A trivialidade é explicada pelo fato de qualquer falante competente da língua portuguesa, que possua o nome "Sócrates" no seu repertório linguístico, está em posição de reconhecer imediatamente como verdadeira a frase "Sócrates chama-se 'Sócrates"'. Mas, de acordo com Kripke (1980), essa teoria não é aceitável à medida que propõe o que deseja explicar: Diz Kripke (1980, p.70):

Perguntamos “A quem ele se refere com 'Sócrates'?" E então a resposta: "Bom, ele se refere ao homem ao qual se refere". Se isto for tudo que há a respeito do significado de um nome próprio, então não se lograria nenhuma referência em absoluto.

Em outras palavras, Kripke (1980) diz que a teoria metalinguística é insatisfatória como teoria da referência.

Entretanto, mais recentemente, Bach (2002) tem sugerido que o argumento da circularidade é equivocado. Basicamente, Kripke relaciona a propriedade "Ser chamado" com "Ser referido" ou "Ser nomeado". Contudo, há uma diferença fundamental a ser considerada: portar um nome ou ser chamado por um nome não é a mesma coisa que ser referido por um nome. Por exemplo, uma coisa é dar a Renato Cartesius o nome de "Descartes", outra coisa é ser referido por esse nome. O mesmo caso de portar um número da cédula de identidade e ser referido por esse número. Com efeito, esclarece Bach (2002, p.101)

Embora seja mais apropriado referir a uma pessoa pelo nome, podemos referir ao invés pelo número de seu seguro social [...] Números e seguros sociais, de fato, não são usados (para referir), mas poderiam ser. Nomes próprios são usados (para referir), mas poderiam não ser.

Portanto, referir e portar um nome são propriedades distintas. Sócrates é chamado 'Sócrates', ele porta esse nome. Dado então que referir é algo que as pessoas fazem ao utilizar a expressão e que o valor semântico é alguma coisa que a expressão tem, e considerando que a teoria metalinguística trata do valor semântico do nome 
próprio, ela não é uma teoria da referência como Kripke (1980) compreende e muito menos viola a condição de não circularidade.

Loar (2006) utiliza-se de um argumento semelhante para dirimir a objeção de circularidade à sua tese. Em sua abordagem metalinguística, considera que o significado convencional de um nome próprio "N" é o mesmo que o significado convencional da descrição definida "A coisa ou a pessoa chamada "N"'. Isto quer dizer que, existe uma relação de sinonímia entre o nome e esta descrição, a qual, de acordo com Loar (2006), age como um qualificador referencial do nome, ${ }^{1}$ que, por sua vez, obtém esse significado com o batismo inicial. Nestas condições, o valor semântico de um nome "N" não pressupõe a referência ou, como ele diz, "o conceito de nome não pressupõe o referir". ${ }^{2}$ Contudo, para além deste significado literal existem, segundo Loar (2006), descrições definidas cujo uso identificador do referente é essencial. E tais descrições transmitem ao final, as intenções individualizadoras e as crenças do falante - numa determinada ocasião de uso daquelas descrições aplicadas a certo particular —, independente da existência deste.

Todavia, argumentos como esses de Loar (2006) não passam incólumes às contestações, como a apresentada por Michael Devitt (2006). Consideremos, por exemplo, o caso, diz Devitt, de uma comunidade de quatro pessoas, cada qual referindo a certo corvo pelo nome "Oscar" - supondo que não há nada anterior na comunidade que transmita a referência (Devitt 2006, p.523). Neste caso, cada um significa com o nome "Oscar", o corvo chamado Oscar na comunidade, conceito exemplificado somente por Oscar. Mas o que faz cada um usar "Oscar" para se referir a Oscar? Parte da resposta é que Oscar é objeto da referência de outro. Mas é essa relação de referência que queremos explicar, ou seja, esse outro refere a Oscar com o nome "Oscar" porque um terceiro o faz, e assim, a abordagem de Loar (2006), segundo Devitt (2006), não explica a relação referencial, exceto, violando a condição de não circularidade.

Ocorre, no entanto que, de acordo com Loar (2006, p.525), é incontroverso que "Em uma teoria causal, assim como no meu tipo de teoria da descrição, a dependência referencial da origem tem que ser acomodada". Tal dependência da origem fica evidenciada no fato da abordagem metalinguística de Loar tomar o uso referencial do nome no passado, como dado fundamental na análise do significado dessa expressão. Em outras palavras, a transmissão do uso referencial do nome na comunidade, a partir de um batismo inicial, explica em virtude do que surgiu a prática de se referir a um determinado particular dessa forma. Loar (2006, p.525) oferece a esse respeito o seguinte exemplo:

Em um tempo zero, Adam batiza certo macaco 'Arnolfo'. Em um tempo um, várias pessoas proferem o enunciado "Arnolfo é F", significando com isso que o macaco batizado por Adam como Arnolfo é tal e tal. Em um tempo dois, certas pessoas tendo esquecido a contribuição de Adam, proferem tais frases,

Principia 19(3): 405-422 (2015). 
que significa o macaco que as pessoas têm referido por 'Arnolfo' é tal e tal. E assim através de um uso contínuo chega-se até o presente.

Nestas condições, como a referência atual se sustenta na referência original no passado, mas não o contrário, não há violação da condição de não circularidade, isto é, obviamente, a referência original não pressupõe ela mesma um referir. Em suma, uma comunidade $\mathrm{C}$, ao batizar um particular $x$, o qual, naquela ocasião, pode ser referido por "o F", com o nome "N", constitui o significado desse nome nos termos da descrição "A pessoa chamada 'N". E arremata Loar (2006, p.526),

Qualquer teoria da referência deve reconhecer tal origem. [...] E espero que esteja claro que, quando refiro a 'origem do uso geral', não é necessário saber como estes manejam sua referência ou como o uso geral foi desenvolvido na dependência dele, exceto, é claro minimamente: que ambos ocorrem via descrição.

$\mathrm{O}$ que é o análogo da afirmação que $\mathrm{N}$ adquiriu a propriedade de portar esse nome, porque foi chamado "N" em um evento original.

Recanati (1997) é outro teórico que, ao defender uma abordagem metalinguística para a análise dos nomes próprios — o que ele chama de visão indexical —, nega que esta abordagem seja circular.

De acordo com ele, o comportamento semântico dos nomes próprios é análogo ao dos indexicais como "você", "agora", "eu". Assim, compreender o proferimento dessas expressões, incluindo nomes próprios, envolve a identificação do referente do termo. Nisto, o ouvinte é como que auxiliado pelo significado do termo referencial. Tanto no caso dos indexicais quanto no dos nomes próprios, o referente varia no contexto. Por exemplo, o token do pronome "Eu" se refere ao falante desse token, de conformidade com a regra linguística que define "eu", como significando "aquele que fala 'Eu', em cada ocorrência particular para se referir a si". Por sua vez, o nome "Sócrates", a depender do contexto de proferimento, tanto pode designar o filósofo grego, quanto o jogador de futebol da seleção brasileira na década de 1980 . No caso dos nomes próprios, o que é linguisticamente transmitido corresponde ao que Recanati (1997, p.138) chama de característica REF (o qualificador referencial segundo Loar, o caráter segundo Kaplan), definida então como a indicação de que "há uma entidade $x$ tal que um proferimento $\mathrm{S}(\mathrm{N})$ é verdadeiro se e somente se $x$ satisfaz $\mathrm{S}(\mathrm{)})$ ". Deste modo, o referente do nome "N" é a entidade que é chamada " $N$ ", ou a entidade que porta o nome "N", em um contexto de proferimento. Em suma, semelhante aos indexicais, cujo significado remete às regras linguísticas - as quais orientam seus usos para referir —, os nomes próprios dispõem de um significado que os caracteriza como expressão linguística, a saber, a característica REF. Assim, o referente de um nome próprio, em todos os casos, é a entidade que porta aquele nome. Eis, portanto, o que Recanati (1997) chama de visão indexical dos nomes próprios.

Principia 19(3): 405-422 (2015). 
Contudo, de acordo com essa concepção, os nomes próprios não transmitem somente a característica REF, mas também um modo de apresentação do referente. Este nada mais é do que toda a informação transmitida pelo nome, em virtude de uma convenção não linguística que permite a individualização do portador. Como tal, esse modo de apresentação do referente não é parte do significado do nome. Portanto,

Em sua estrutura, um nome próprio refere por uma convenção linguística a quem quer que ocorra ser o portador do nome, mas quem (o que) é o portador do nome é relativa ao contexto, uma matéria não linguística, uma matéria de convenção social. A referência do nome, assim, depende do fator contextual como a referência de uma expressão indexical. (Recanati 1997, p.140).

Nestas condições, de acordo com Recanati (1997), sua abordagem não viola a condição de não circularidade. Por uma razão muito simples: não se trata de uma teoria completa da referência, mas uma teoria parcial, no seguinte sentido: explica apenas o primeiro estágio do caráter referencial dos nomes próprios, isto é, argumenta que a referência do token de um nome próprio depende da referência do nome-tipo na comunidade. Complementa, então, Recanati (1997, p.159): "Se [essa ideia] fosse apresentada como uma teoria completa da referência, poderia ser talvez, circular, ao menos vazio, pois explicaria a referência em termos de referência." Contudo, enquanto teoria parcial da referência, escapa à objeção de circularidade, ao assumir, em linhas gerais, as razões de Loar (2006) e Evans (1982), a saber: enquanto num primeiro estágio a regra semântica captura o determinante da referência, uma análise completa desse caráter referencial dos nomes exige que se enfatize o papel dos fatores sociais. Estes fatores permitem, de acordo com a versão metalinguística de Recanati, focalizar o importante papel dos utilizadores atuais e do passado da comunidade - os "produtores" como diz Evans; ou a "origem causal" como diz Loar (2006) - , cujo uso e referência particular do nome determinam o uso e a referência geral daquela expressão. Em suma, desde que um falante competente da língua é um conhecedor dessa língua, ele sabe, ao proferir um nome próprio "N", que essa expressão refere ao particular chamado " $\mathrm{N}$ " na comunidade. E a referência dessa expressão na comunidade é determinada pela prática de outros, no passado da comunidade e atualmente.

Penso que a nota comum em todas essas análises é a de que, o referir de um nome próprio é sempre contextual, portanto, a unicidade do designatum não pertence ao nome-tipo, isto é, não pertence ao qualificador referencial ou propriedade REF. É o uso do nome que nos conecta ao referente estrito.

Nesta linha de argumentação, acrescento o seguinte: como vejo o problema, nomes próprios na abordagem metalinguística que estou a defender, exemplificam propriedades $N$-sort. Uma propriedade "sort" ou "espécie" é aquela como "ser um coelho", 
"ser uma cadeira", "ser uma mesa", etc. Assim, um indivíduo chamado "N" exemplifica a propriedade " $N$-sort" ou da "Espécie N". A questão principal concernente à exigência de não circularidade, diz respeito, a meu ver, à natureza da propriedade "ser chamado N" ou "ser o portador de N". Esta propriedade deve remeter a uma disposição por parte do falante, em associar "N" a um designatum. O falante deve estar propenso a escolher entre os indivíduos que carregam o nome, aquele que é o designatum do nome, orientado por fatores como o contexto do seu proferimento, as suas crenças e suas percepções. Sendo assim, a singularidade da referência por um nome próprio é um fenômeno da pragmática.

\section{Argumento modal}

Em Naming and Necessity (1980), Kripke apresenta várias objeções ao modelo descritivista de conteúdo. O argumento modal é uma dessas objeções. ${ }^{3}$ A teoria metalinguística é somente um caso particular, ao qual o argumento se aplica.

A intuição por trás do argumento é que nomes próprios continuam a se referir à mesma pessoa, com respeito aos mundos possíveis, nos quais o indivíduo deixa de ter algumas das propriedades com as quais o identificamos; contudo, isso não pode incluir as propriedades essenciais que ele possui, em todos os mundos possíveis. Os nomes próprios são assim, designadores rígidos.

Consideremos o nome "Aristóteles", usado para se referir ao famoso filósofo grego, nascido em Estagira no século $\mathrm{V}$ a.C. Consideremos ainda as propriedades que os falantes associam ao nome "Aristóteles" em uma ocasião particular, a saber, "O criador da lógica silogística" e "O Aluno mais famoso de Platão" e "O fundador do Liceu", e "O mestre de Alexandre, o Grande". Estas propriedades são usadas como critérios para identidade de Aristóteles. Chamemos de F o conjunto dessas características associadas ao nome "Aristóteles". Nestas condições, alguém é Aristóteles se, e somente se, for portador de F. As descrições funcionam como sinônimos do nome "Aristóteles". Portanto, a proposição "Aristóteles é o portador de F", se constitui numa verdade necessária - verdadeira em todos os mundos possíveis. Mas ocorre que Aristóteles poderia não ter nenhuma das propriedades a ele associadas. É um fato contingente que Aristóteles tenha sido "O criador da lógica silogística" e "O aluno mais famoso de Platão" e "O fundador do Liceu" e "O mestre de Alexandre, o Grande". Portanto, a proposição "Aristóteles é o portador de F" expressa uma verdade contingente. Logo, o conteúdo ou valor semântico de nome próprio não pode ser dado em termos de modo de apresentação, em particular, o significado do nome "Aristóteles" não pode ser dado em termos descritivos, os quais apresentam atributos contingentes de Aristóteles.

O que Kripke (1980) alude, aplicado à teoria metalinguística é o seguinte:

Principia 19(3): 405-422 (2015). 
(i) Se N significa "O portador de 'N"', então a frase "N poderia não ter sido o portador de N" deveria ser falsa.

(ii) Mas "N poderia não ter sido o portador de N" é verdadeiro.

(iii) Logo, $\mathrm{N}$ não significa "O portador de 'N"'.

Ora, de acordo com a teoria metalinguística, o significado de um nome próprio "N" é dado pela descrição "O portador de 'N"'. Mas, de acordo com Kripke (1980), o conteúdo dos nomes próprios não pode ser dado em termos de descrições definidas, em particular, em termos de descrições metalinguísticas. Consequentemente, cabe aos proponentes da tese metalinguística o ônus da demonstração em contrário. Duas réplicas tomadas dos proponentes mais recentes da teoria serão aqui aduzidas, a saber, a levantada por Recanati (1997) e aquela sugerida por Loar (2006) e Bach (2002).

Recanati (1997, p.156-7) objeta o seguinte: o argumento modal está baseado na alegação R abaixo:

(R) Se o significado de uma expressão referencial $s$ é constituído por certo conceito $\mathrm{F}$, de modo tal que a referência de $s$ é apresentado como sendo $\mathrm{F}$, então 's é F' é analítico e, portanto, necessário.

O problema, segundo Recanati (1997), é que esta alegação se apoia em um vínculo questionado por Kripke entre aprioricidade (analiticidade) e necessidade. ${ }^{4} \mathrm{Com}$ efeito, dizer um enunciado como "Eu estou a proferir este proferimento", é verdadeiro em função de seu significado, ou seja, trata-se de um enunciado analítico. Contudo, o referente do indexical "Eu" pode variar segundo aquele que fala. Logo a proposição expressa é contingente. Portanto, o enunciado, pode ser compreendido a priori, ainda que a proposição que ele expresse seja contingente.

Paralelo a esta distinção entre aprioricidade e necessidade, consideremos a diferença entre conteúdo e caráter (character), firmada por Kaplan (1989, p.733-8). O conteúdo é a proposição expressa e o caráter de uma expressão é definido pelas convenções linguísticas e, por seu turno, determina o conteúdo de uma expressão em todo o contexto, isto é, produz um conteúdo verdadeiro em todo o contexto. Em virtude disso, uma frase como "Eu estou aqui agora", é analítica. Assim, assumindo esta distinção, modifica-se (R): agora é preciso afirmar que (1) se o conteúdo de uma expressão referencial s é constituído por certo conceito $\mathrm{F}$, tal que o referente de $s$ é apresentado como sendo F, então "s é F" é necessário. Mas também, é possível afirmar (2) se o caráter de uma expressão referencial $s$ é constituído por certo conceito $\mathrm{F}$, de modo tal que a referência de $s$ é apresentada como sendo F, então "s é F" é a priori. De acordo com Recanati (1997), o argumento modal pode apoiar-se em (1), desde que (2) não envolva necessidade. Considere por exemplo o nome "Sócrates", tendo como valor semântico a descrição "O portador de 'Sócrates"'. Considere ainda que a 
pessoa Sócrates seja apresentada nos termos dessa descrição. Desde que a pessoa Sócrates poderia não ter sido "O portador de "Sócrates"”, não é necessário que Sócrates tivesse esse nome. Ao que parece, então, a descrição "O portador de 'Sócrates" não pode constituir o conteúdo do nome, antes é constitutivo do caráter. Logo, declarar, por exemplo, que o nome "Sócrates" significa "O portador de 'Sócrates" é a priori verdadeiro.

Loar (2006) e Bach (2002) por sua vez, questionam a validade formal do argumento modal, reproduzindo a alegação de Dummett (1981) a respeito. Segundo esses filósofos, o modo de Dummett evitar o argumento modal, explicaria a tese da rigidez semântica dos nomes próprios de Kripke e, ao mesmo tempo, é compatível com a premissa descritivista de que os nomes próprios equivalem às descrições definidas.

Contrariando Kripke (1980), Dummett (1981, p.113-7) argumenta que a diferença entre o nome próprio e as descrições definidas não é semântica, mas uma diferença sintática. Isso é demonstrado a partir da ideia de que, há certa ambiguidade envolvendo a interpretação do valor de verdade de alguns enunciados modalizados, contendo descrições definidas, como, por exemplo, em "a mãe de Maria poderia não ter sido a mãe de Maria”. Segundo Dummett (1981, p.114), temos duas maneiras de analisar o escopo lógico da descrição definida, tal como ocorre no enunciado. Assim, se tomarmos que a descrição definida "a mãe de Maria", em "a mãe de Maria poderia não ter sido a mãe de Maria", ocorre dentro do escopo do operador modal, obtemos a seguinte análise do enunciado:

$$
\diamond \exists y(\forall x(M x \leftrightarrow x=y) \& \neg M y)
$$

em que My abrevia “y é mãe de Maria”.

Essa maneira de analisar o enunciado dá conta, justamente, segundo Dummett, daquele caso em que o proferimento do enunciado não afirma uma proposição verdadeira. Em tal caso, temos a descrição com um escopo estreito em relação ao operador modal. No entanto, o valor de verdade do enunciado muda, se for estabelecido que a descrição definida ocorra fora do escopo do operador modal, caso em que teríamos a seguinte análise:

$$
\exists y(\forall x(M x \leftrightarrow x=y) \& \neg \diamond M y) .
$$

Desse modo, de acordo com Dummett (1981), ao considerarmos que a descrição "a mãe de Maria" tem escopo amplo com respeito ao operador modal, obtemos o sentido segundo o qual é verdadeiro afirmar que, a mãe de Maria poderia não ter sido a mãe de Maria. Portanto, temos duas interpretações possíveis de enunciados modalizados, contendo descrições definidas. Num primeiro caso, assumindo que a descrição "a mãe de Maria" tem escopo estreito em "a mãe de Maria poderia não ter sido a mãe de Maria”, a descrição definida não é rígida. No segundo caso, a descrição é rígida, pois segundo Dummett, (1981, p.128) "estamos tratando a descrição

Principia 19(3): 405-422 (2015). 
definida enquanto tendo, como seu referente constante, o referente que ela tem no mundo real".

Com base nessa distinção, Dummett (1981, p.127-8) assume o ponto de vista de que, nas linguagens naturais, há uma convenção estabelecendo que nomes próprios tenham sempre escopo amplo, em enunciados contendo operadores modais. Assim, um enunciado modalizado como "Santa Ana poderia não ter sido a mãe de Maria" poderia ser analisado da seguinte maneira:

$$
\exists y(y=s \& \diamond \neg M y),
$$

em que $s$ representa Santa Ana e $M y$ abrevia "y é a mãe de Maria".

Aqui, o nome próprio "Santa Ana" ocorre fora do escopo do operador modal, com isso, o portador do nome no mundo atual permanece constante nos mundos possíveis, ou, em termos kripkeanos, "Santa Ana" é um designador rígido. Portanto, de acordo com Dummett, é possível demonstrar a distinção entre nomes próprios e descrições definidas, sem postular diferença semântica.

Voltando agora ao argumento modal, tal como expresso acima,

(i) Se N significa "O portador de 'N"', então a frase "N poderia não ter sido o portador de N" deveria ser falsa.

(ii) Mas "N poderia não ter sido o portador de N" é verdadeiro.

(iii) Logo, $\mathrm{N}$ não significa "O portador de 'N"'.

De acordo com Loar (2006), a premissa (i) do argumento incorre num equívoco, pois uma vez que, no consequente, $\mathrm{N}$ é tomado sob o âmbito do operador modal de possibilidade, tem um escopo mais amplo do que quando tomado fora da modalidade, como acontece no antecedente. Em outras palavras, embora seja verdade que $\mathrm{N}$ significa "O portador de N", isso não implica em dizer que o enunciado "N pode não ter sido o portador de N" seja falso, pois aqui N está sob a regência do operador modal, tendo assim uma extensão maior. Neste sentido, diz Loar (2006) que o argumento é semanticamente ambíguo; isto é, o argumento falha à medida que as premissas não podem ser ambas verdadeiras.

Entretanto, observando atentamente o argumento modal, o que ele diz? A rigor diz o seguinte: se o nome próprio "N" e a descrição "o F" são semanticamente equivalentes, então o consequente da premissa (i) tem que ser verdadeiro. Ocorre que "N" e a descrição "o F" têm comportamentos modais distintos: O nome próprio é um designador rígido, e a descrição é um designador flexível. Logo a premissa (ii) é verdadeira. Daí, por modus tollens, "N" não significa "o F".

Outra réplica se serve da distinção feita por Dummett (1991) entre o conteúdo assertórico e o ingrediente de sentido. O conteúdo assertórico é o que é dito pelo proferimento, é também objeto das atitudes proposicionais. O ingrediente de sentido é a

Principia 19(3): 405-422 (2015). 
contribuição dos enunciados simples para os enunciados complexos dos quais fazem parte. Para ilustrar a distinção, consideremos o exemplo em que o nome "Quine" é introduzido na linguagem como "O autor de Word and Object". Neste caso, a frase (S1) tem o mesmo significado que (S2).

(S1) Quine é o autor de Word and Object

(S2) Quine é Quine

Logo, (S1) e (S2) têm o mesmo conteúdo assertórico, dizem a mesma coisa. Por outro lado, consideremos o enunciado (S3).

(S3) Quine poderia não ter sido o autor de Word and Object.

Aqui, (S1) e (S2) fazem diferentes contribuições para (S3), como podemos constatar, pelo fato do enunciado (S4) ser verdadeira, enquanto (S5) é falso.

(S4) O autor de Word and Object poderia não ter sido o autor de Word and Object

(S5) Quine poderia não ter sido Quine

Resultado: (S1) e (S2), embora tenham o mesmo conteúdo assertórico, diferem quanto ao ingrediente de sentido.

Em seu argumento original, Kripke (1980) explica a distinção entre (S1) e (S2), a partir da noção de designador rígido. (S2) é verdadeiro por estabelecer uma relação de identidade entre designadores rígidos, o que não ocorre em (S1), que é igualmente verdadeiro, mas não é uma relação de identidade ou sinonímia. O que Dummett (1991) afirma é que esta diferença está no ingrediente de sentido. Porém, à luz de seus conteúdos assertóricos, (S1) e (S2) são idênticos, isto é, dizem a mesma coisa. E, portanto, a noção de designação rígida atende a exigências da sintaxe modal e como o nome tem um escopo mais amplo, não se presta como fundamento de distinções semânticas.

Assim, algumas conclusões são sugeridas: (1) é incorreto inferir, com Kripke e sua tese da rigidez dos nomes próprios, que "N" e "o F" têm diferentes comportamentos semânticos; (2), a única coisa que podemos concluir é que diferem em termos de ingredientes de sentido; (3) a diferença no ingrediente de sentido de "N" e "o F" não implica diferença em seus conteúdos assertóricos; finalmente, (4) o argumento modal falha em demonstrar que nomes próprios não têm conteúdo descritivo, desde que consideremos as descrições como conteúdo assertórico dos nomes.

\section{Considerações finais}

É interessante lembrar que, a tese metalinguística para explicar o comportamento semântico dos nomes próprios é uma tese minoritária na discussão sobre o tema. Por

Principia 19(3): 405-422 (2015). 
outro lado, os programas sobre os quais se debruça grande parte da literatura filosófica - a saber, o programa descritivista e o programa da referência direta e teoria histórico causal —, não resultaram, até o momento, em uma explicação satisfatória para o mecanismo da referência singular através de um nome próprio. Procurei demonstrar que, as possíveis vantagens dos modelos semânticos majoritários, sobretudo, o modelo kripkeano - base na qual se apoiam as objeções examinadas — não tornam mais instável ou menos provável o modelo metalinguístico de explicação do significado ou valor semântico dos nomes próprios. Olhando nesta perspectiva, os modelos descritivistas/fregueanos e modelos millianos/kripeanos não estão em melhor situação que a tese metalinguística.

Penso, conforme procurei frisar, que a teoria metalinguística é uma teoria do valor semântico do nome e não uma teoria da referência, embora as objeções a ela dirigidas procurem evidenciar este último aspecto. Isso permite tomar o nome próprio como uma variável sortal e inseri-la no léxico de uma língua, ao mesmo tempo, permite oferecer uma explicação mais plausível para a abertura semântica destas expressões. Argumentos mais precisos em relação a este último aspecto fugiriam aos objetivos do presente artigo. Deixo para examinar este ponto em outro trabalho.

\section{Referências}

Abbott, B. 2004. Proper names and language. In: N. G. Carlson; J. F. Pelletier (eds.) Reference and quantification: the partee effect, p.1-19. USA: Center for the study of language and information.

Bach, K. 1981. What's in a name? Australasian Journal of philosophy 59(4): 371-386.

— 1994. Descriptivism Distilled. URL: http://online.sfsu.edu/ kbach/oldies/descriptivism.html.

- 2002. Giorgione was so-called because of his name. Philosophical Perspectives 16: 73-103.

Castañeda, H. N. 1988. Thinking, language and experience. Minneapolis: University of Minnesota Press.

Dummett, M. 1981. Frege Philosophy of language. 2nd ed. Cambridge: Harvard University Press.

- 1991. The logical basis of metaphysics. London: Duckworth.

Devitt, M. 2006. Brian Loar on singular terms. In: M. Davidson (ed.) On sense and direct reference: readings in the philosophy of language, p.517-24. Mcgraw-Hill.

Devitt, M.; Sterelny, K. 1999. Language and Reality: An introduction to the philosophy of language. Oxford: Blackwell.

Evans, G. 1982. The varieties of reference. Oxford: Oxford University Press.

Katz, J. 1994. Names Without Bearers. Philosophical Review 103(1): 1-39.

Kaplan, D. 1989. Demonstratives: An essay on the semantics, logic, metaphysics, and epistemology of demonstratives and other indexicals. In: J. Almog; J. Perry; H. Wettstein (eds.) Themes from Kaplan, p.481-579. New York: Oxford university press.

Principia 19(3): 405-422 (2015). 
Kneale, W. 1962. Modality De Dicto and De Re. In: E. Nagel; P. Suppes; A. Tarski (Eds.) Logic, Methodology, and Philosophy of Science, p.622-33. Stanford: Stanford University Press.

Kripke, S. 1980. Naming and Necessity. Cambridge: Harvard University Press.

Loar, B. 2006. The semantics of singular terms. In: M. Davidson (ed.) On sense and direct reference: readings in the philosophy of language, p.496-516. Mcgraw-Hill.

Russell, B. 1905. On Denoting. Mind 14(56): 479-493.

Recanati, F. 1997. Direct Reference: from language to thought. Massachusetts: Blackwell.

Schiffer, S. 1978. The Basis of Reference. Erkenntnis 13: 171-206.

Josailton FERnANdes MENDONÇA

Universidade do Estado do Rio Grande do Norte - UERN

Programa de Pós-Graduação da Universidade Federal do Ceará - UFC

BRASIL

josailtonf@gmail.com

\section{Notas}

${ }^{1}$ De acordo com Loar (2006, p.497) "[...] the function of a singular term is to introduce an individual concept into what is meant or expressed on its particular uses.[...] The concepts which they do literally express are normally non-individuating, class concepts, which we might call referential qualifiers; so, for example, being an oak, and being female, are referential qualifiers of "that oak" and "she" [...]."

${ }^{2}$ No original: Now the concept of name is clearly not presupposed in my account of 'refers', and since to dub is to make known a decision or agreement to use a certain vocable to refer to certain thing, neither does the explication of ' $x$ was dubbed N' presuppose the concept of name. (Loar 2006, p.513).

${ }^{3}$ A literatura põe em evidência ainda e principalmente o argumento semântico e o argumento epistêmico. Por fugir aos objetivos do artigo, não tratarei dessas objeções aqui.

${ }^{4}$ Kripke (1980, p.38-43) mostra corretamente, que aprioricidade não equivale à necessidade, mas ele também distingue entre aprioricidade e analiticidade. A primeira é uma noção epistemológica e a segunda é semântica. Um enunciado analítico sempre é necessário, mas um enunciado a priori pode ser contingente (e.g, 'um metro é a medida do metro-padrão').

Principia 19(3): 405-422 (2015). 